\title{
PELATIHAN PENGOLAHAN DATA PENELITIAN BERBASIS SOFTWARE STATISTIK UNTUK MAHASISWA di JABOTABEK
}

\author{
${ }^{1}$ Daryati, ${ }^{2 *}$ Riyan Arthur, ${ }^{3}$ Tommy Eka Miharja, ${ }^{4}$ Nasaruddin, ${ }^{5}$ Nur Rochimah \\ ${ }^{1,2}$ Pendidikan Vokasional Konstruksi Bangunan, Universitas Negeri Jakarta \\ ${ }^{3}$ Dosen Universitas Pancasakti Bekasai \\ ${ }^{4}$ Dosen STKIP Pancakarya Tangerang \\ ${ }^{5}$ Dosen STKIP Muhammadiyah Bogor \\ Email Korespondensi: arthur@unj.ac.id
}

\begin{abstract}
This service is carried out on the basis of statistics which is considered a difficult science because there are many formulas that require accuracy and precision in their calculations. As well as the many problems of students' inability to access data processing software caused by the low level of literacy in students. This service is a training activity for data processing research based on statistical software that aims to improve the quality of human resources through the ability of students to process research data. The partners of this service are universities around JABOTABEK with a focus on training activities on statistical software-based data analysis techniques such as SPSS and JASP for final year students at JABOTABEK. The methods used in this training activity include lectures, discussions, questions and answers, direct demonstrations and assignments. These methods were developed according to the current situation and conditions. The target to be achieved in the implementation of this activity is to improve the ability of students to carry out data analysis with the help of software such as SPSS and JASP. In addition, as an output, coaching participants are expected to be able to use SPSS and JASP software in thesis and research which can then be uploaded.
\end{abstract}

Keywords: Statistics, SPSS, JASP, Data Processing Skills, Students.

\begin{abstract}
Abstrak
Pengabdian ini dilakukan atas dasar ilmu statistika yang dianggap sebagai ilmu yang sulit karena terdapat banyak rumus yang membutuhkan ketelitian dan kecermatan dalam perhitungannya. Serta banyaknya permasalahan ketidakmampuan mahasiswa dalam mengakses software pengolahan data yang diakibatkan oleh rendahnya tingkat literasi pada mahasiswa. Pengabdian ini merupakan kegiatan pelatihan pengolahan data penelitian berbasis software statistik yang bertujuan untuk meningkatkan kualitas SDM melalui kemampuan mahasiswa dalam mengolah data penelitiannya. Mitra pengabdian ini adalah Perguruan tinggi sekitar BODETABEK dengan fokus kegiatan pelatihan teknik analisa data berbasis software statistik seperti SPSS dan JASP bagi mahasiswa tingkat akhir di BODETABEK. Metode yang digunakan dalam kegiatan pelatihan ini antara lain dengan ceramah, diskusi, tanya jawab, demonstrasi langsung dan penugasan. Metode-metode tersebut dikembangkan sesuai dengan situasi dan kondisi saat ini. Target yang akan dicapai dalam pelaksanaan kegiatan ini adalah meningkatkan kemampuan mahasiswa dalam melalukan analisis data dengan bantuan software seperti SPSS dan JASP. Selain itu sebagai luaran peserta pembinaan diharapkan mampu menggunakan software SPSS dan JASP dalam skripsi dan riset yang kemudian dapat di unggah.
\end{abstract}

Kata kunci: Statistika, SPSS, JASP, Keterampilan Olah Data, Mahasiswa

\section{PENDAHULUAN}

Perguruan tinggi di era digital ini menjadi salah satu lembaga pendidikan yang sangat berperan melahirkan sumber daya manusia (SDM) yang bermutu demi memenuhi kebutuhan pembangunan (Noor, 2010). Mutu perguruan tinggi sudah seharusnya ditingkatkan secara merata sesuai dengan kebutuhan wilayah agar tiap daerah dapat memaksimalkan potensi yang dimilikinya (Rufaidah et al., 2019). Oleh karena itu BODETABEK (Bogor, Depok,
Tangerang dan Bekasi) sebagai daerah penyangga DKI Jakarta, kualitas SDM-nya harus adaptif, cekatan, inovatif, kreatif mengikuti perkembangan modernisasi dan digitalisasi teknologi informasi terkini. Usaha meningkatkan kualitas SDM di perguruan tinggi dapat dilakukan melalui penelitian, penulisan artikel ilmiah yang membangun pola pikir kritis dan analitis mahasiswa. Perkembangan pola pikir tersebut akan membentuk lulusan memiliki kualitas tinggi untuk bersaing di dunia industri. 
Penelitian merupakan cara paling efektif untuk melatih penalaran analisa seorang mahasiswa sebelum memasuki dunia pekerjaan sesungguhnya. Dalam proses menyelesaikan perkuliahannya mahasiswa khususnya strata 1 (S-1) akan dihadapkan dengan pembuatan tugas akhir berupa penelitian dalam bentuk penyusunan skripsi (Fikri et al., 2019). Skripsi merupakan syarat wajib yang harus dipenuhi oleh mahasiswa ketika akan mendapatkan gelar menjadi Seorang Sarjana. Biasanya Skripsi dilakukan pada semester akhir yaitu semester 7 dan 8. Jangka waktu pengerjaan skripsi sekitar 6 (enam) bulan sampai satu tahun (Fadilla \& Salim, 2021). Setiap skripsi selalu berkaitan dengan data. Mulai dari proses pengumpulan, penyajian, analisis, interpretasi sampai penarikan kesimpulan data membutuhkan ilmu pengolahan yang disebut statistika. Penelitian adalah suatu kegiatan ilmiah yang wajib dilakukan mahasiswa pada perguruan tinggi sebagai suatu usaha untuk menemukan, mengembangkan, dan menguji kebenaran suatu pengetahuan (Suharsimi, 2006). Penelitian melatih mahasiswa untuk lebih tanggap terhadap lingkungan sekitarnya, baik lingkungan tempat tinggal maupun lingkungan pendidikan (Irawan, Handayani, Hasan, \& Zohri, 2021). Kunci dalam sebuah penelitian terdapat pada proses analisa data. Pada proses tersebut data yang diperoleh digunakan untuk menginterpretasikan sebuah hasil penelitian. Untuk menganalisis data dalam sebuah ilmu statistika memerlukan kerja keras, pola pikir dan kemampuan intelektual yang tinggi agar hasil yang didapat tepat dan memuaskan. Bagi Sebagian mahasiswa, ilmu statistika dianggap sebagai ilmu yang sulit karena terdapat banyak rumus yang membutuhkan ketelitian dan kecermatan dalam perhitungannya. permasalahan. Statistika adalah ilmu yang mempelajari bagaimana caranya mengumpulkan data, menyederhanakan data, menyajikan data, dan membuat kesimpulan berdasarkan informasi yang diperoleh dari sampel (Rosana, 2016). Statistika memegang peranan penting dalam pengembangan ilmu pengetahuan. Terdapat bermacam-macam teknik statistik yang dapat digunakan dalam penelitian khususnya dalam pengujian hipotesis (Sugiyono, 2019).

Seiring perkembangan teknologi informasi dan era digital, banyak inovasi berbagai program komputer yang dirancang khusus untuk memudahkan pengolahan data statistik tanpa mengurangi ketepatan hasilnya. Salah satu program analisis data yang dapat dipakai dalam analisis data kuantitatif adalah Program Statistical Product and Service Solutions (SPSS) dan Jeffreys's Amazing Statistics Program (JASP). Program ini dikenal sangat handal dalam membantu para peneliti untuk melakukan uji dan analisis statistik (Panjaitan \& Firmansyah, 2018). SPSS dan JASP merupakan aplikasi program statistik dengan kemampuan perhitungan statistik yang tinggi, sehingga memudahkan pengguna dalam analisis data. Program seperti SPSS dan JASP umum digunakan sebagai alat bantu analisis yang cepat juga tepat sehingga tidak lagi digunakan perhitungan manual. SPSS merupakan aplikasi program statistik dengan kemampuan perhitungan statistik yang tinggi, sehingga memudahkan pengguna dalam analisis data (Riyanto \& Nugrahanti, 2018). Selain itu untuk menunjang hasil penelitian data kuantitatif digunakan alat uji statistik, yang salah satunya adalah penggunaan program SPSS (Fauziah \& Karhab, 2019). Hasil dari pelaksanaan pelatihan $86 \%$ mahasiswa tidak lagi mengatakan mengolah data itu sulit dan artinya para mahasiswa sudah memahami dalam menggunakan aplikasi SPSS (Hustia, Arifai, Afrilliana, \& Novianty, 2021). Namun, pada kenyataannya banyak mahasiswa yang tidak adaptif dengan modernisasi yang terjadi. Sebagian mahasiswa mengaku gaptek (gagap teknologi) sehingga kesulitan dalam mengakses program komputer. Meskipun saat ini banyak buku tutorial penggunaan software analisis data diterbitkan untuk memudahkan mahasiswa dalam mengakses program. Akan tetapi rendahnya tingkat literasi mahasiswa membuat usaha tersebut kurang efektif sehingga dibutuhkan bantuan pelatihan yang lebih 
spesifik dan serius agar penyerapan pengetahuan dan keterampilan dapat dimaksimalkan (Hasyim \& Listiawan, 2014).

Pelatihan statistik beserta program statistik diadakan dalam rangka memenuhi permintaan mahasiswa yang sedang mengerjakan tugas akhir di perguruan tinggi BODETABEK. Oleh karena itu, kami selaku tim pengabdian merasa terpanggil untuk dapat melaksanakan pengabdian masyarakat ini karena merasa bertanggung jawab atas keberhasilan mahasiswa dalam pendidikan dengan pemanfaatan teknologi komputer, yang akhirnya dapat digunakan dalam penyusunan tugas akhir, dan juga dalam dunia kerja mereka nantinya. Berdasarkan observasi sebelumnya dari tim pengabdi juga ditemukan kesulitan yang dihadapi mahasiswa terkait pengolahan data menggunakan alat-alat statistik beserta program aplikasinya.

Dari permasalahan ini, perlu solusi kongkrit dengan melaksanakan program pengabdian kepada masyarakat tepatnya mahasiswa yang sedang mengerjakan tugas akhir khususnya di perguruan tinggi BODETABEK. Dengan kegiatan pengabdian ini, diharapkan mahasiswa tidak lagi melakukan kesalahan dalam metodologi penelitian. Fakta ilmiah yang dihasilkan dapat dipertanggungjawabkan kebenarannya dan dapat dijadikan sebagai acuan dalam pengambilan kebijakan dengan meningkatkan mutu pendidikan.

\section{METODE PELAKSANAAN}

Alur penelitian sebaiknya disajikan di bagian ini dilengkapi dengan keterangan gambar. Keterangan gambar diletakkan menjadi bagian dari judul gambar (figure caption) bukan menjadi bagian dari gambar. Metode-metode yang digunakan dalam penyelesaian pengabdian dituliskan di bagian ini.

kegiatan pelatihan ini antara lain dengan ceramah, diskusi, tanya jawab, demonstrasi langsung dan penugasan. Metode-metode tersebut dikembangkan sesuai dengan situasi dan kondisi saat ini. Sasaran kegiatan ini adalah mahasiswa $\mathrm{S} 1$ tingkat akhir pada berbagai perguruan tinggi di BODETABEK.

Target yang akan dicapai dalam pelaksanaan kegiatan ini adalah meningkatkan kemampuan mahasiswa dalam melalukan analisis data dengan bantuan software seperti SPSS dan JASP. Selain itu sebagai luaran peserta pembinaan diharapkan mampu menggunakan software SPSS dan JASP dalam skripsi dan riset yang kemudian dapat di unggah.

Strategi yang dapat dilakukan untuk melakukan analisis data dengan software dapat dijabarkan sebagai berikut :

1. Memahami konsep ilmu statistika dan teknik analisis data sehingga dapat mengkategorikan data penelitian

2. Mengklasifikasikan tingkat skala pengukuran data (skala nominal, Ordinal, Interval, atau Rasio)

3. Dilakukan uji validitas dan realibilitas terlebih dahulu terhadap data yang akan dianalisis.

4. Melakukan Analisis data dengan pengecekan data, mentabulasi data, menerapkan data sesuai pendekatan penelitian seperti penelitian deskriptif, penelitian asosiasi (korelasi), atau penelitian komparasi.

5. Menggunakan software analisis data seperti SPSS dan JASP untuk menganalisis data dengan metode statistika yang sesuai, bisa dengan Metode Statistika Deskriptif atau metode Statistika Inferensial

6. Menggunakan hasil analisis yang dapat berupa narasi, tabel, grafik atau lain sebagainya.

Untuk menyelesaikan masalah mitra, maka dibutuhkan narasumber dengan kepakaran tertentu. Dalam pelatihan kali ini, kriteria yang dibutuhkan dari narasumber adalah

1. Ahli dalam pengolahan data berbasis software khususnya SPSS dan JASP.

2. Dosen ilmu statisika yang memahami proses pengolahan data pada sebuah penelitian.

Adapun mahasiswa perguruan tinggi yang terlibat dalam pelatihan adalah sebagai berikut: 


\begin{tabular}{cl}
\hline No & \multicolumn{1}{c}{ Nama Perguruan Tinggi } \\
\hline 1 & Universitas Pancasakti \\
\hline 2 & STKIPPancakarya \\
\hline 3 & STKIP Muhammadiyah Bogor \\
\hline 4 & Universitas Gunadarma \\
\hline 5 & President University \\
\hline 6 & Universitas Faletehan \\
\hline 7 & STAI Darul Qalam \\
\hline 8 & IPB \\
\hline 9 & Universitas Serang Raya \\
\hline
\end{tabular}

Sumber: Dokumen P2M FT UNJ

\section{HASIL DAN PEMBAHASAN}

Hasil dan pembahasan berisi hasil-hasil temuan penelitian dan pembahasannya secara ilmiah. Tuliskan temuan-temuan ilmiah (scientific finding) yang diperoleh dari hasilhasil pengabdianataupenelitian yang telah dilakukan tetapi harus ditunjang oleh data-data yang memadai. Temuan ilmiah yang dimaksud di sini adalah bukan data-data hasil pengabdian/penelitian yang diperoleh. Temuantemuan ilmiah tersebut harus dijelaskan secara saintifik meliputi: Apakah temuan ilmiah yang diperoleh? Mengapa hal itu bisa terjadi? Mengapa trend variabel seperti itu? Semua pertanyaan tersebut harus dijelaskan secara saintifik, tidak hanya deskriptif, bila perlu ditunjang oleh fenomena-fenomena dasar ilmiah yang memadai. Selain itu, harus dijelaskan juga perbandingannya dengan hasil-hasil para peneliti lain yang hampir sama topiknya.

Pengolahan data adalah bagian terpenting dalam mendukung studi dan pekerjaan. Oleh karena itu, aplikasi pengolahan data sangat diperlukan. Bagi pengelola perguruan tinggi, aplikasi pengolahan data akan berguna untuk mendukung pekerjaan sehari-hari dan bahan mentah untuk membangun sebuah sistem informasi. Sedangkan bagi mahasiswa, aplikasi pengolahan data akan berguna dalam banyak hal yaitu mahasiswa dapat menentukan kualitas informasi secara cepat, akurat, dan relevan. Seiring dengan perkembangan teknologi, salah satu aplikasi pengolahan data yang sering digunakan saat ini adalah aplikasi SPSS (Statistical Product and Service Solution) dan Jeffreys's Amazing Statistics Program (JASP). Aplikasi SPSS dan JASP adalah salah satu program atau aplikasi di bidang statistik yang mampu memproses data statistik secara cepat dan akurat. Aplikasi SPSS dan JASP menjadi sangat popular karena memiliki bentuk pemaparan yang baik (memiliki grafik dan tabel), bersifat dinamis (mudah dilakukan perubahan data), dan mudah dihubungkan dengan aplikasi lain dalam preparasi data sampel analisis.

Kegiatan pelatihan ini merupakan salah satu dari kegiatan pengabdian kepada masyarakat yang ditujukan kepada mahasiswa, khususnya untuk membantu dalam melakukan analisa data penelitian tugas akhir. Pelaksanaan pelatihan pengolahan data menggunakan aplikasi SPSS dan JASP dilaksanakan kepada mahasiswa di perguruan tinggi BODETABEK. Waktu pelaksanaannya pada tanggal 20 Februari 2021 dan 27 Februari 2021, yang berlangsung pada pukul 09.00 WIB sampai 12.00 WIB, dengan dihadiri sekitar 118 orang mahasiswa sebagai peserta pelatihan. Kegiatan yang dilakukan berupa penyampaian materi mengenai cara mengoperasikan program SPSS dan JASP beserta cara menginterpretasikan hasil pengolahan data tersebut.

Pelatihan dilakukan untuk membantu mahasiswa dalam analisis data dari hasil penelitian yang dilakukan. Dalam pengembilan suatu keputusan terhadap suatu perlakuan tentu data yang didapat harus diolah terlebih dahulu dengan baik dan benar sehingga yang disampaikan adalah hasil yang akurat dan sesuai dengan keadaan sebenarnya. Untuk mengolah data tersebut, mahasiswa membutuhkan statistik untuk memenuhi hasil yang akurat. Statistik adalah mata kuliah yang pada umumnya dapatkan di bangku perkuliahan (Nainggolan et al. 2017). Namun kendalanya, ketika berada di semester tingkat akhir mahasiswa mengalami kesulitan dalam melaksanakan penelitian saat mengolah dan menganalisis data statistika (Ismail and Safitri). Sehingga kegiatan 
sosialisasi dan pelatihan analisis data statistika umumnya adalah solusi yang dilakukan untuk mengatasi kesulitan mahasiswa tersebut (Syaleh, 2020).

Simulasi pengolahan data dan teori statistik yang diberikan mampu membuat mahasiswa lebih memahami statistik dan teknik analisis data dengan program SPSS dan JASP. Mahasiswa yang paham mengolah data dengan statistika dan SPSS mengalami peningkatan seperti pada gambar 1. Pemahaman penggunaan program SPSS mahasiswa meningkat sebesar $2.5 \%$. Berdasarkan persentase peningkatan pemahaman menunjukan bahwa, pelatihan penggunaan program SPSS dan JASP dapat membantu mahasiswa menjadikan penelitiannya layak untuk dijadikan rujukan dalam pengmabilan keputusan dalam pengembangan pendidikan. Hal ini diperkuat oleh (Pasaribu et al., 2018) yang menyatakan Penggunaan Software SPSS dapat menganalisis data dalam jumlah besar, memiliki paket analisis data yang lebih bervariasi sehingga dapat meningkatkan efektifitas dan efisiensi dalam pengolahan data.

Pelatihan menimbulkan efek yang positif pada mahasiswa. Mahasiswa lebih menyadari peranan statistikan dan penggunaan program SPSS dan JASP dalam mengolah data penelitian. Kegiatan banyak diisi dengan diskusi dan tanya jawab. Kegiatan sangat interaktif yang diselenggarankan dengan diskusi terbuka. Peserta bisa menanggapi setiap saat jika tidak paham dengan materi yang disampaikan. Model pembelajaran seperti ini akan membuat mahasiswa lebih paham dikarenakan langsung memperoleh jawaban dari pemateri. Setelah pelatihan selesai, peserta juga dapat memberikan feedback terhadap pelatihan tersebut yang hasilnya akan dijadikan bahan evaluasi untuk pelatihan pengabdian selanjutnya. Adapun beberapa kekurangan dan kelebihan yang terjadi saat pelatihan berlangsung yaitu: perlu adanya praktik langsung menggunakan software pengolahan data statistik, dikarenakan sedang terjadi pandemi covid19 terjadi kendala sinyal masing-masing peserta dalam menyimak materi yang diberikan, waktu pelaksaan kegiatan hari pertama dan kedua terlalu jauh sehingga membuat peserta lupa akan materi yang sebelumnya, materi yang diberikan sangat lengkap dan mudah pahami, pemateri sangat interaktif, dan peserta meminta untuk sering diadakannya kegiatan pelatihan yang sama agar memudahkan peserta untuk mengolah dan mengintepretasikan data. Berikut adalah hasil pre test dan post test pemahaman menggunakan SPSS dan JASP dan hasil feedback peserta terhadap pelatihan pengolahan data penelitian berbasis software statistik.

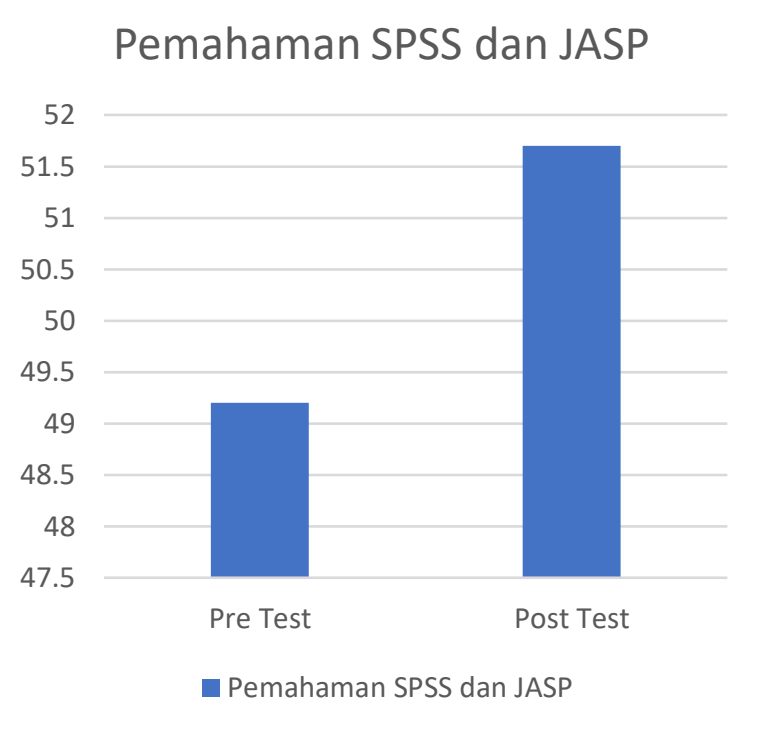

Gambar 1. Hasil Pre test dan Post test Pemahaman Penggunaan SPSS dan JASP

Feedback Pelatihan SPSS dan JASP

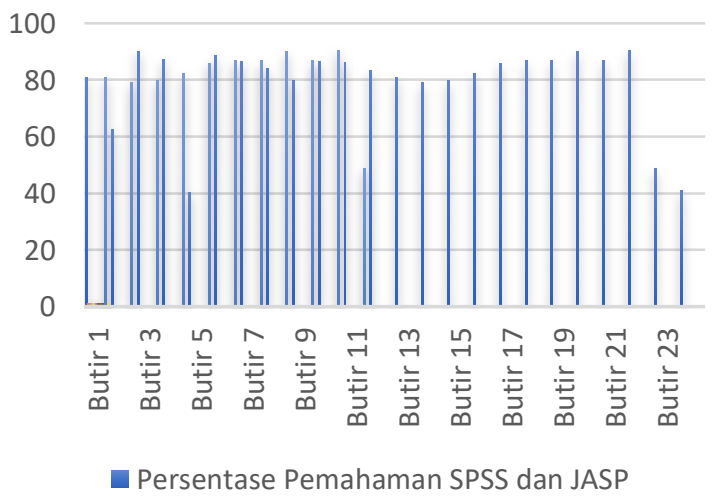

Gambar 2. Hasil Feedback Peserta terhadap Pelatihan SPSS dan JASP 


\section{KESIMPULAN}

Berdasarkan hasil analisis proses pelatihan data penelitian berbasis software statistik dapat disimpulkan bahwa tingkat pemahaman mahasiswa tentang statistika lebih meningkat menggunakan program SPSS dan JASP dengan interpretasi data dari 49,2\% menjadi $51,7 \%$. Kegiatan ini sebaiknya dilaksanakan setiap tahun guna mempermudah mahasiswa dalam penyelesaian tugas akhir dan memperbaiki mutu serta kualitas dari karya ilmiah mahasiswa.

Dengan berakhirnya kegiatan pelatihan peserta memberikan feedback yang positif terhadap kegiatan tersebut dengan interpretasi data $79 \%$. Adapun beberapa saran yang diberikan peserta dalam mengikuti kegiatan pelatihan data penelitian berbasis software statistik yaitu: terjadi kendala sinyal dari beberapa peserta dalam memahami materi yang disampaikan, perlu dilakukan praktik langsung untuk menggunakan program pengolahan data statistik, rentang waktu kegiatan hari pertama dan kedua terlalu jauh, materi sangat lengkap dan mudah dipahami, dan pemateri sangat interaktif.

\section{UCAPAN TERIMA KASIH}

Pengabdian ini didanai oleh Dana Hibah Pengabdian Masyarakat Fakultas Teknik Universitas Negeri Jakarta. Diucapkan terima kasih kepada Fakultas Teknik Universitas Negeri Jakarta, Universitas Pancasakti Bekasi, STKIP Muhammadiyah Bogor dan STKIP Panca Karya Tangerang beserta seluruh pihak yang telah membantu atas kelancaran kegiatan ini hingga selesai. Tanpa mengurangi rasa hormat, mohon maaf kami tidak bisa menuliskan nama satu per satu.

\section{DAFTAR PUSTAKA}

Fadilla, \& Salim, A. (2021). Pelatihan Penggunaan Aplikasi SPSS sebagai instrumen Pengolahan dan Pengujian Data Penelitian Kuantitatif. AKM: Aksi
Kepada Masyarakat Jurnal Pengabdian Kepada Masyarakat, 2(1), 35-46.

Fauziah, F., \& Karhab, R. S. (2019). Pelatihan Pengolahan Data Menggunakan Aplikasi SPSS Pada Mahasiswa. Jurnal Pesut: Pengabdian Untuk Kesejahteraan Umat, 1(2), 129-136.

Fikri, M. El, Irawan, \& Siregar, N. (2019). Pelatihan Analisis Data Berbagai Model Untuk Meningkatkan Kemampuan Mahasiswa Dalam Pengolahan Data Penelitian Berbasis Program Spss. Universitas Pembangunan Panca Budi, Juni(17), 1476.

https://doi.org/10.1017/CBO97811074 15324.004.

Hasyim, M., \& Listiawan, T. (2014). Penerapan Aplikasi IBM SPSS Untuk Analisis Data Bagi Pengajar Pondok Hidayatul Mubtadi' in Ngunut Tulungagung Demi Meningkatkan Kualitas Pembelajaran dan Kreativitas Karya Ilmiah Guru. Jurnal Pengabdian Kepada Masyarakat, 2(1), 28-35.

Hustia, A., Arifai, A., Afrilliana, N., \& Novianty, M. (2021). Pelatihan Pengolahan Data Statistik Menggunakan Spss Bagi Mahasiswa. JMM: Jurnal Masyarakat Mandiri, 5(4), 1-8.

Irawan, J., Handayani, A. A. A. T., Hasan, L., \& Zohri, N. (2021). Operasionalisasi IBM SPSS 21 untuk Meningkatkan Kemampuan dan Keterampilan Olah Data Penelitian Mahasiswa. JPMPI: Jurnal Pengabdian Magister Pendidikan IPA, 4(2).

Ismail, R., \& Safitri, F. (2019). Peningkatan Kemampuan Analisa Dan Interpretasi Data Mahasiswa Melalui Pelatihan Program SPSS. Jurnal Masyarakat Mandiri, 3(2), 148-155.

Nainggolan, E., Mariah, S., \& Kurniawan, F. (2017). Internalisasi Asumsi Pembelajaran Andragogi Pada Mata 
Kuliah Statistik. Jurnal Keluarga Sehat Sejahtera, 15(1).

Noor, I. H. (2010). Penelitian dan Pengabdian Masyarakat pada Perguruan Tinggi. Jurnal Pendidikan Dan Kebudayaan, 16(3), 285. https://doi.org/10.24832/jpnk.v16i3.46 2.

Panjaitan, D. J., \& Firmansyah. (2018). Pelatihan Pengolahan Data Statistik dengan Menggunakan SPSS. Prosiding Seminar Nasional Hasil Pengabdian, 1(1), 40.

Pasaribu, F. T., Multahadah, C., Febrianti, A., \& Asiani, R. W. (2018). Pelatihan peningkatan kemampuan analisis data penelitian menggunakan software SPSS bagi pemuda RT. 14 Perumnas Aurduri Indah Kota Jambi. Jurnal Karya Abdi Masyarakat, 2(1), 62-69.

Riyanto, S., \& Nugrahanti, F. (2018). Pengembangan Pembelajaran Statistika Berbasis Praktikum Aplikasi Software SPSS dengan Bantuan Multimedia untuk Mempermudah Pemahaman Mahasiswa terhadap Ilmu Statistika. Journal of Computer and Information Technology, 1(2), 62-67.

Rosana, D., \& Setyawarno, D. (2016). Statistik terapan untuk penelitian pendidikan. Yogyakarta.

Rufaidah, A., Izzah, N., Sofiyannurriyanti, Suparno, \& Ririn, M. (2019). Program Pengabdian Masyarakat Melalui Workshop Analisis Program Studi Teknik Industri Bantuan Pemerintah terhadap Peningkatan Mutu. Jurnal Terapan Abdimas, 4, 104-112.

Sugiyono, 2019. Statistika untuk Penelitian. Bandung : Alfabeta.

Suharsimi, A. (2006). metodelogi Penelitian. Yogyakarta: Bina Aksara.

Syaleh, H. (2020). Pelatihan Program Statistic Product and Service Solution (SPSS) bagi Mahasiswa dan Dosen Sekolah Tinggi Ilmu Ekonomi H. Agus Salim Bukittinggi. Community Engagement and Emergence Journal (CEEJ), 1(1), 14-21. 